\title{
Incidental Detection of a Rare Inverted and Impacted Maxillary Third Molar in a Patient of Mandibular Unicystic Ameloblastoma
}

\section{Ching-Yi Chen ${ }^{1}$, Wen-Chen Wang ${ }^{1,2}$, Li-Min Lin ${ }^{1,2}$ and Yuk-Kwan Chen ${ }^{1,2 *}$}

${ }^{1}$ Division of Oral Pathology \& Maxillofacial Radiology, Department of Dentistry, Kaohsiung Medical University Chung-Ho Memorial Hospital, Kaohsiung, Taiwan

${ }^{2}$ School of Dentistry, College of Dental Medicine, Kaohsiung Medical University, Kaohsiung, Taiwan

\begin{abstract}
Reviewing the literatures, the most frequently impacted tooth was mandibular third molar, followed by the maxillary third molars, the maxillary canines and the mandibular premolars. The current case report aimed to present a rare inverted and impacted maxillary third molar incidentally detected in a patient of mandibular unicystic ameloblastoma on panoramic radiography, highlighting the importance of thorough radiographic examination of any jawbone lesions to detect the potential occurrence of other dental anomalies using panoramic radiography.
\end{abstract}

Keywords: Impaction; Inversion; Third molar; Maxilla; Ameloblastoma

\section{Introduction}

Owing to impedance by the jawbone, adjacent tooth, or the thickened gingival tissues, impacted teeth cannot erupt completely into the oral cavity within the predictable period [1-3]. Dearth of dental arch length and space are also considered as the chief cause for tooth impaction. Reviewing the literatures, mandibular third molar was the most frequently impacted tooth, followed by the maxillary third molars, the maxillary canines and the mandibular premolars [3-7]. The aim of the current case report was to present a rare inverted and impacted maxillary third molar incidentally detected in a patient of mandibular unicystic ameloblastoma.

\section{Case Report}

A 27-year-old Taiwanese male with the chief complaint of painful sensation over the right submandibular region was referred to the Emergency Department of our institution from a local dental clinic. Antibiotic and analgesics were then prescribed, but the patient still complained that the painful sensation has not been relieved. So, the patient visited the Dental Department of our institution in the next day. Intraoral examination revealed a partially erupted right mandibular third molar with reddish inflamed surrounding tissues was noted. Furthermore, partially erupted right maxillary third molar and left mandibular third molar teeth were also found. On the other hand, no eruption of the left maxillary third molar was detected. The panoramic radiography revealed a well-defined unilocular ovoid-shaped corticated radiolucency containing a well-developed horizontal impacted third molar over the right mandibular body, measured approximately $2.0 \times 3.0$ $\mathrm{cm}$ in maximum diameter (Figure 1). Thus, a clinical impression of dentigerous cyst, keratocystic odontogenic tumor or unicystic odontogenic tumor was considered. Also worth tonote on panoramic radiographic examination, a well-developed inverted maxillary third molar impaction was incidentally found in the left tuberosity area adjacent to the distal aspect of the left maxillary sinus; a disto-angular impacted right maxillary third molar and a horizontal impacted left mandibular third molar were also noted (Figure 1). Under general anesthesia, the right mandibular lesion was totally enucleated together with the removal of the right horizontal impacted third molar tooth. The surgical specimen was submitted for pathologic examination. Histopathological diagnosis of the surgical specimen revealed unicystic ameloblastoma. On the other hand, due to the potentially development of odontogenic cysts/tumors from the impactions over the other three quadrants of the jaws, these three impactions were simultaneously surgically extracted during the operation of the right mandibular lesion after a fully discussion with the patient. The postoperative course of the patient was uneventful. The patient has been undergone routine followup and no sign of recurrence has been noted.

\section{Discussion}

The significance of the present case report is to describe a rare case of inverted and impacted maxillary third molar in a patient of mandibular unicystic ameloblastoma. We assume that there could not be possible association between the occurrence of this dental anomaly and the mandibular benign odontogenic tumor in our patient. However, reviewing English literatures, the frequency of the inverted impacted maxillary third molar has been uncommon. Since the first reported case by Gold and Demby [8], to the best of our knowledge, including the current case, a number of 12 cases of inverted impacted maxillary third molar teeth have been reported [8-16]. Importantly, almost all of

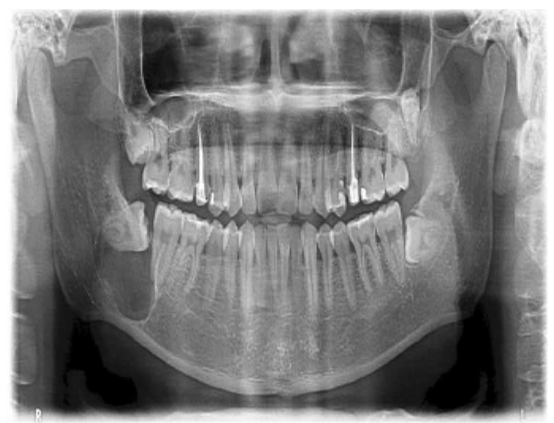

Figure 1: An inverted left maxillary third molar impaction was incidentally noted during the examination of the right mandibular radiolucence lesion.

*Corresponding author: Yuk-Kwan Chen, School of Dentistry, College of Dental Medicine, Kaohsiung Medical University, 100 Shih-Chuan 1st Road, Kaohsiung, Taiwan, Tel: +886-3121101 7017; Fax: +886-7-3210637; E-mail: k0285@ms22.hinet.net

Received February 18, 2014; Accepted February 24, 2014; Published February 26, 2014

Citation: Chen CY, Wang WC, Lin LM, Chen YK (2014) Incidental Detection of a Rare Inverted and Impacted Maxillary Third Molar in a Patient of Mandibular Unicystic Ameloblastoma. Dentistry 4: 213. doi:10.4172/2161-1122.1000213

Copyright: $\odot 2014$ Chen $\mathrm{CY}$, et al. This is an open-access article distributed under the terms of the Creative Commons Attribution License, which permits unrestricted use, distribution, and reproduction in any medium, provided the original author and source are credited. 
Citation: Chen CY, Wang WC, Lin LM, Chen YK (2014) Incidental Detection of a Rare Inverted and Impacted Maxillary Third Molar in a Patient of Mandibular Unicystic Ameloblastoma. Dentistry 4: 213. doi:10.4172/2161-1122.1000213

these cases have been detected using panoramic radiography indicating the importance of this examination tool to detect any potential dental anomalies. Impacted teeth are typically painless; however, pain may occur due to infection of surrounding tissues, as shown in the present case, or pressure on the mandibular nerve in deeply positioned mandibular third molar impactions [1,17]. Moreover, presence of impacted teeth affects the adjacent teeth to have periodontitis and tooth decay $[18,19]$. Hence, the impacted teeth could usually need to be surgically removed. However, potential complications such as dislodgment into other anatomical structures or perforation of the maxillary sinus that could arise from surgical extraction of inverted and impacted teeth should be cautiously deliberated in advance. These should be evaluated against the advantage of surgical removal. Moreover, the surgical intervention for inverted molars is more challenging than other types of impactions due to the abnormal position of the crown renders it greatly inaccessible that needs extensive bone removal, excessive bone loss as well as nerve damage is the main drawback in such circumstances. Nevertheless, as aforementioned, due to the possible growth of odontogenic cystic or tumorous lesions in future, the inverted impacted maxillary third molar of the present case was surgically extracted together with the right mandibular lesion, as have also been surgically removed in a number of the previously documented cases $[8,9,12,15,16]$. We reported, to our knowledge, the first case of the co-existence of inverted third impacted maxillary third molar with a mandibular ameloblastoma during the examination of this mandibular lesion. Furthermore, the current case highlights the importance of thorough radiographic examination of any jawbone lesions to detect the potential occurrence of other dental anomalies using panoramic radiography.

\section{References}

1. Kruger G (1984) Oral maxillofacial surgery. (6thedn), Mosby Co, Saunders, London.

2. Petterson, Ellis E, Hupp J, Tucker M (1998) Contemporary oral and maxillofacial surgery. (3rdedn), CV Mosby, Philadelphia.

3. Brakus I, Filipovic Z, Boric R, Siber S, Svegar D, et al. (2010) Analysis of impacted and retained teeth operated at the department of Oral Surgery, School of Dental Medicine, Zagreb. Coll Antropol 34: 229-233.

4. Chu FC, Li TK, Lui VK, Newsome PR, Chow RL, et al. (2003) Prevalence of impacted teeth and associated pathologies - a radiographic study of the Hong Kong Chinese population. Hong Kong Med J 9: 158-163.

5. Tarzona BA, Paredes VB, Llamas JM, Cibrian RE, Gandia JL (2010) Influence of first and second premolar extractions or non-extraction treatments on mandibular third molar angulation and position. A comparative study. Med Oral Patol Oral Cir Bucal 15: 760-766.

6. Padhye MN, Dabir AV, Girotra CS, Pandhi VH (2013) Pattern of mandibular third molar impactions in the Indian population: a retrospective clinicoradiographic survey. Oral Radiol Oral Surg Oral Med Oral Pathol 116: e161-166.

7. Zuccati GC, Doldo T (2010) Multiple impactions in an adolescent girl. Am J Orthod Dentofacial Orthop 137: 163-172.

8. Gold J, Demby N (1973) Rare inverted maxillary third molar impaction: report of case. J Am Dent Assoc 87: 186-188.
9. Held HW (1979) Inverted maxillary molar. Dent Radiogr Photogr 52: 87. 10.

10. AIShamrani SM (2001) Inverted and impacted maxillary third molar. Report of two cases. Odontostomatol Trop 24: 15-17.

11. Pai V, Kundabala M, Sequeira PS, Rao A (2008) Inverted and impacted maxillary and mandibular 3rd molars; a very rare case. Oral Health Comm Dent 2: 8-9.

12. Yuvaraj, Agarwal GD (2011) Inverted maxillary third molar impaction - A case report. People's J Sci Res 4: 57-58.

13. Mohan S, Kankariya H, Fauzdar S (2012) Impacted inverted teeth with their possible treatment protocols. J Maxillofac Oral Surg 11: 455-457.

14. Togoo RA (2013) Rare occurrence of inverted maxillary third molar impaction: a case report. J Int Oral Health 5: 85-87.

15. Rammal M, Alfonso C (2013) An unusual case of an inverted and impacted maxillary third molar. Oral Surg (in press).

16. Chhabra S, Chhabra N, Dhillon N (2012) Inverted and impacted maxillary third molar - Removal by lateral transposition method. Int J Dent Exper Dent Sci 1 : 26-29.

17. Obiechina AE, Arotiba JT, Fasola AO (2001) Third molar impaction: Evaluation of the symptoms and pattern of impaction of mandibular third molar teeth in Nigerians. Odontostomatol Trop 24: 22-25.

18. Bataineh AB, Al QM (2003) The predisposing factors of pericoronitis of mandibular third molars in a Jordanian population. Quintessence Int 34: 227231.

19. Macluskey M, Slevin M, Curran M, Nesbitt R (2005) Indications for and anticipated difficulty of third molar surgery: a comparison between a dental hospital and a specialist high street practice. Br Dent J 199: 671-675. 